\title{
Inflammatory bowel diseases: current therapeutic approaches and potential of using stem cells
}

\begin{abstract}
Inflammatory bowel diseases (IBDs) are chronic and progressively deteriorating in nature without many promising curative treatments. Chronic inflammation of not well defined origins is considered to be the root cause of the problem which affects intestinal mucosa with or without transmural involvement. IBDs are divided in two main categories: Crohn's disease (CD) and ulcerative colitis (UC). While there is no long lasting cure for IBDs, current therapies can only reduce the causative inflammatory process with the hope to induce long-term remission. Treatment modalities for the IBDs are still evolving. The increased understanding of the underlying immunopathology has helped identify new targeted treatment options like immunosuppressive antibodies directed against signaling molecules. Use of stem cells, which are capable of modulating the immune system, can offer a long lasting relief to the patients suffering from the disease. The goal for stem cell-based therapy is to achieve long lasting cure, if not a permanent one. To achieve this, it would be desirable to obtain cell types, whether genetically modified or naturally occurring, having a high migratory ability in addition to homing ability into the afflicted parts of intestine. These cells should also have high in vivo survival potential, and then be able to regulate the immune reaction without provoking any response from the host's immune system and repair the injured tissue. Hematopoietic stem cells (HSC) and mesenchymal stromal cells (MSC) therapies are being investigated as a treatment for IBDs. MSC therapy is well tolerated and has minimal established side-effects compared to HSC therapy, which involves ablative chemotherapy. Several clinical studies using MSCs have been initiated and some early results suggest several inherent problems. In each study, optimization of MSC therapy appears to be the most urgent problem, which can be resolved only by scientifically unveiling the mechanisms of therapeutic action of stem cells. In this review, we summarize current therapies for IBDs and recent advances in the field of stem cell therapy, which offer promise to become the next generation treatment of choice.
\end{abstract}

Keywords: intestinal epithelium, ablative chemotherapy, hematopoietic stem cells, long-term remission, immunosuppressive antibodies
Volume 2 Issue 2 - 2017

\author{
Tripurari Mishra,' Aditi Sarswat, ${ }^{2}$ Kirtishri \\ Mishra, ${ }^{3}$ Anand S Srivastava ${ }^{4}$ \\ 'Department of Surgery, University of Illinois-Metropolitan \\ Group Hospitals, USA \\ 2Department of Anesthesia, Henry Ford Hospital, USA \\ ${ }^{3}$ Department of Urology, University Hospitals Cleveland Medical \\ Center, USA \\ ${ }^{4}$ Global Institute of Stem Cell Therapy and Research, USA
}

Correspondence: Anand S Srivastava, Chairman and Cofounder, Global Institute of Stem Cell Therapy and Research, 4370 La Jolla Village Drive, 4th Floor, San Diego, California 92I22, USA, Tel 8583442492, Email anand@giostar.com

Received: November 21, 2016 | Published: February 20, 2017
Abbreviations: IBDs, inflammatory bowel diseases; CD, crohn's disease; UC, ulcerative colitis; HSC, hematopoietic stem ce1ls; MSC, mesenchymal stromal cells

\section{Introduction}

The intestinal epithelium carries out multiple, indispensable functions to maintain the homeostasis of a body and also demonstrates immense potential to continue to regenerate. However, this layer is frequently damaged by various gastrointestinal reasons and repair of damaged intestinal epithelium becomes increasingly difficult with advancing age. IBDs, caused by inflammation of not well defined origins, also contribute to the damage of intestinal linings. Affecting a vast number of people in almost all parts of the world, IBDs being chronically afflicting and degenerative in nature often lead to debilitating lifetime condition that has a significant impact on quality of life. ${ }^{1}$ The disease affects every aspect of patients' lives including mental wellbeing and physical health in addition to the profound impact it has on personal relationships and work productivity. ${ }^{2}$ More than a million people suffer from degenerative GI tract diseases in the US every year. ${ }^{3,4}$ The exact cause contributing to seeding and progression of IBDs is not well deciphered but it is thought that either local inflammation for some unknown reasons or hyper immune response towards gut flora contributes to causation and progression of the disease. Over the time such immune responses lead to degenerative losses in intestinal tissues. Also, it is suspected to be an autoimmune disease, thought to be initiated by uncontrolled immune response towards high load of intestinal flora.

IBDs, because of their chronic nature, force demand of continuous and extended care of the patients and thus economic impact of health care cost adds up to a significant amount. Cost of taking care of patients with $C D$ can vary in range of $\$ 18,000-\$ 29,000$ per year. 4,5 In this way, the medial cost of taking care of the IBD suffering patients inflicts a significant economic dent to the individual and to related family, and compromises the quality of life of the individuals suffering from the disease. Making things worse, the conventional treatments offer only a temporary relief and usually demand a long term medical attention. In this review we will try to visit different currently practiced treatment methods, and also, if cell therapy can offer a better promise to patients. Stem-cell therapy is emerging as a promising alternative to treat ongoing tissue damage during IBD possibly by altering the mucosal immune response. ${ }^{6}$ Recent advances in the stem cell biology of the gastrointestinal tract have provided 
major breakthroughs, such as in vitro culture of intestinal stem cells (ISCs), and have also shed light on the transplantation of the cells with objective to repair the damaged intestinal mucosa. Several concluded and ongoing studies show promising yet inconclusive results. The outcomes obtained from past and current clinical trials have potential to add a new branch of disease management for patients with IBD, and thus significantly improving the quality of life $(\mathrm{QoL})$.

\section{Etiopathogenesis of ibd and symptoms}

Though IBDs are commonly recorded in populations all over the world and significant advances have been made into understanding of its pathogenesis, but understanding of the exact cause leading to condition has been elusive. Several agents have been attributed to cause or contribute to IBD. Both genetic and environmental factors appear to play roles in the pathogenesis of IBD, and thus lead to changes in innate and adaptive immune function, microbiome composition, and disruption in epithelial barrier function. These causes, suspected to be rooted in environmental factors, genetic makeup of individuals or exposure to different set of microbes lead to diverse immune responses. Autoimmune activation is also suspected because of presence of circulating antibodies against epithelial barrier function and commensal enteric bacterial population. ${ }^{7,8}$ In both, UC and $\mathrm{CD}$, antibodies against a range of autoantigens including lymphocyte antigens are present. ${ }^{9}$ Atypical perinuclear antineutrophil cytoplasmic antibodies (P-ANCAs) and anti-Saccharomyces cerevisiae antibodies (ASCAs) are two most commonly studied auto antibodies in autoimmune diseases. ${ }^{10}$ Duerr et al. ${ }^{11}$ showed presence of P-ANCAs in $60-75 \%$ of UC patients with primary sclerosing cholangitis. ${ }^{11}$ Other studies also show autoimmunity against human tropomyosin isoform 5 (hTM5) as a critical epithelial auto antigen in UC, which can ignite both cellular and humoral immune responses. ${ }^{10,12,13}$ These hTM5-specific immunoglobulin G (IgG) auto antibodies show a direct pathogenic effect on the destruction of colonic epithelial cells. On the other hand genetic contribution in the disease is demonstrated by prevalence of $C D$ in siblings. Occurrence of $C D$ is 30 times more likely in siblings comparison to normal population..$^{14,15}$ The same report also demonstrates a frame shift mutation in NOD2 gene. Other well documented genes mutations which may increase the risk of developing CD are ATG16L1, ${ }^{16,17}$ IL1R, ${ }^{18}$ SLC11A1. ${ }^{19}$

Sustained excessive microbial load induces inflammatory response in the colon, where the bacterial load is very high usually. ${ }^{20}$ Lately, it is also thought that $\mathrm{CD}$ might be caused by impaired innate immunity. Another view towards understanding the etiology of IBD is either loss of tolerance to or increased intolerance to intraluminal bowel antigens. ${ }^{21}$ Irrespective of the views about the condition, a wider accepted fact is that $\mathrm{CD}$ is caused by impaired hyper response by immune system. These diseases associated with chronic inflammation can affect the intestinal mucosa with or without transmural mucosal involvement.

Symptoms of active disease include abdominal pain, diarrhea, unintended weight loss, and most commonly fatigue. ${ }^{22,23}$ These symptoms, very commonly seen in cases of IBD, are debilitating which can be easily seen in non-related conditions. In addition blood in stool, reduced appetite are also commonly seen symptoms in patients suffering from IBDs. Because the exact mechanisms leading to IBD are still not established and well understood, current medical treatments for IBD are aimed at minimizing the discomfort, often by the way of anti-inflammatory drugs, antibiotics and immunosuppression which cover all three suspected causes of IBD i.e. bacterial overload, inflammation, and autoimmunity.

$\mathrm{CD}$ : $\mathrm{CD}$ is a chronic condition characterized by inflammation, irritation, and/or swelling in the GI tract. Commonly, CD affects the small intestine and the beginning of the large intestine; however, the disease can affect any part of the GI tract from the esophagus to perianal area. ${ }^{24}$ Chronic, uncontrolled inflammation of the intestinal mucosa in CD demonstrates segmental transmural mucosal inflammation and granulomatous changes. Common symptoms of $\mathrm{CD}$ include abdominal pain, diarrhea with or without blood in stool depending upon the degree of inflammation. With increasing severity of the disease, CD can lead to anemia, and also to other complications like nausea, loss of appetite, fever, skin rashes, arthritis and chronic fatigue. Because of systemic effect of the disease and poorly defined causes, $\mathrm{CD}$ is often difficult to treat.

$\mathrm{UC}$ : $\mathrm{UC}$ is another form of IBD which is very much similar to $\mathrm{CD}$ but affects mostly large intestine. It typically presents with shallow, continuous inflammation extending from the rectum proximally to include the entire colon. Fistulas, fissures, abscesses, and smallbowel involvements are usually absent. It is characterized by constant diarrhea with blood. The incidence of UC ranges between 1.2 to 20.3 cases per 100,000 persons per year, and its prevalence can vary between 7.6 to 246.0 cases per 100,000 per year. ${ }^{25}$ Mutations in glutathione S-transferases and methylene tetra hydrofolate reductase genes have a strong association with UC. ${ }^{26}$

UC just like CD presents with diarrhea, weight loss, anorexia, tenesmus and mucoid or bloody stools. Proctoscopy may show friable mucosa. Extra-intestinal manifestations include erythema nodosum, pyoderma gangrenosum, episcleritis, uveitis, and iritis. UC is also associated with ankylosing spondylitis and primary sclerosing cholangitis. The similarities and differences are recorded in Table 1.

Table I Comparison of clinical manifestations in UC and CD

\begin{tabular}{lll}
\hline Clinical manifestation & UC & CD \\
\hline Fever & Less Likely & More Likely \\
Vomiting & Less Likely & More Likely \\
Diarrhea & Less Likely & More Likely \\
Abdominal pain & Less Likely & More Likely \\
Bleeding per rectum & More Likely & Less Likely \\
Ileum/Small Bowel & Unlikely & Commonly \\
Rectal involvement & Commonly & Less Likely \\
Semental involvement & Unlikely & Commonly \\
& Mucosa and & Full Thickness \\
Depth of involvement & Submucosa & \\
Fat Creeping onto serosa & Unlikely & More Likely \\
Thickened BowelWall & Unlikely & More Likely \\
Granulomatous disease & Unlikely & More Likely \\
Sclerosing Cholangitis & More Likely & Less Likely
\end{tabular}

Therapies: As mentioned above, inflammation rooted either in misdirected immune response which may be ignited by diverse reasons, or in autoimmune reaction towards some gut antigen are the leading theories on etiology of IBD. ${ }^{11-13,27}$ These reactions set off inflammation cascades which lead to disruption of the intestinal barrier layer. Therefore, most of the therapeutic approaches focus on inhibiting inflammation by using anti-inflammatory drugs, antibiotics, 
or by attenuating the inflammatory pathway by neutralizing one or other participating molecules of the inflammation reaction cascade or by cutting down the immune response by immunosuppression. A general treatment course has been depicted in Figure 1. The current treatments for IBD are centered around the suppressing the symptoms and discomfort in a stepwise approach. These usually begin with anti-inflammatory medications derived from 5-aminosalicylic acid (5-ASA) agents with or without antibiotics, subsequently, followed by corticosteroids, immunomodulators, and biologics. When all else fail, as an more aggressive effort surgery is opted. ${ }^{28}$ Almost half of CD patients, who develop fistulas, require surgical resection at some point in their disease course. ${ }^{29}$

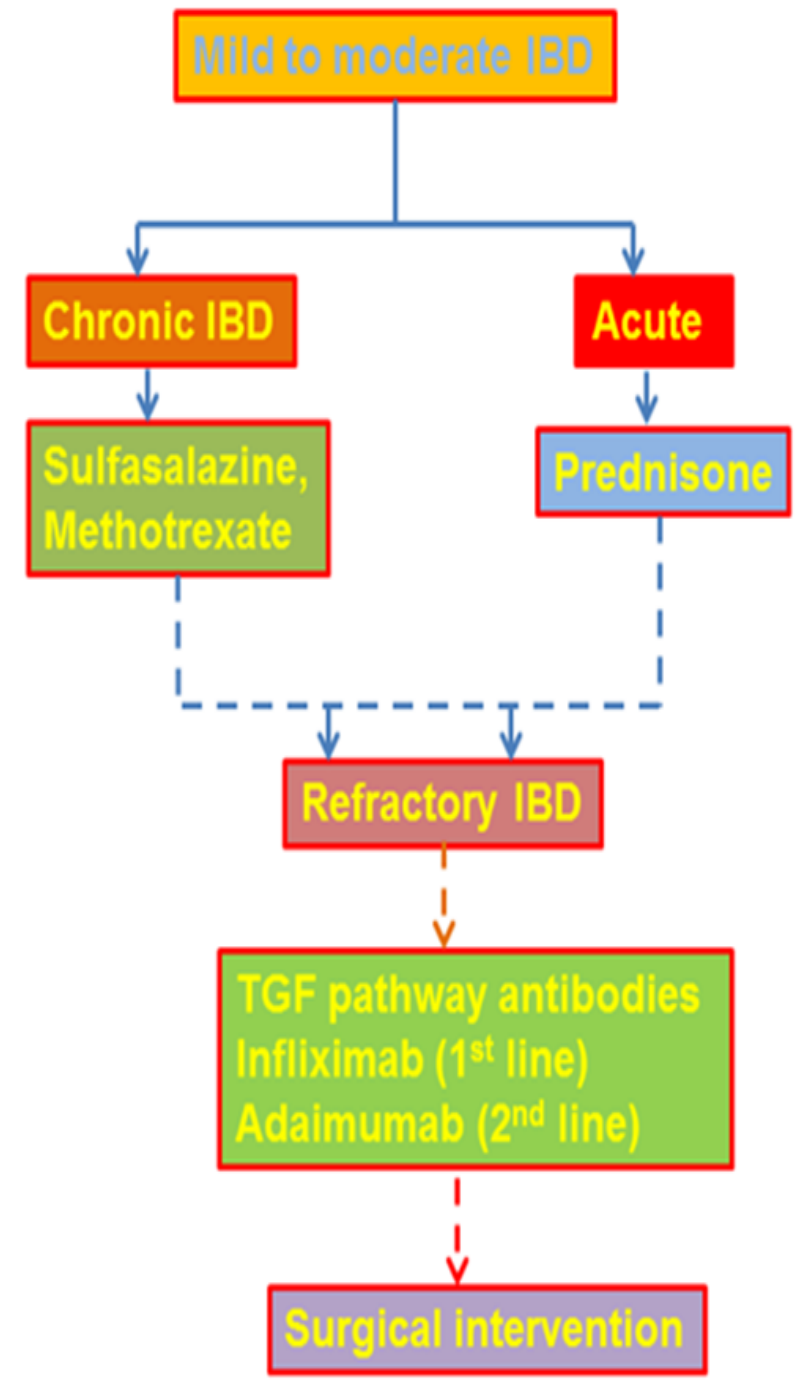

Figure I Mild to moderate IBDs are first treated with drugs of 5-ASA group with or without methotrexate combination. Acute IBDs are treated with corticosteroids to bring the inflammation under control and then with other immunological drugs like those of 5-ASA group and methotrexate. When these drugs are not effective, immuno- modulators like cyclosporine are used. Advent of new inflammation pathway targeting antibodies has made it possible to target specific pathways like in IBD TNF pathway targeting biologicals are used.

\section{5-Aminosalicylic acid compounds}

Anti-inflammatory drug sulfasalazine (SASP) has been used for treating UC for decades since it was approved for clinical application. ${ }^{30}$ The oldest and most economical of the 5-ASA compounds, sulfasalazine is composed of sulfapyridine and 5-ASA molecules. However, a major segment of the treated population reports significant side effects of the drug such as indigestion, nausea, vomiting, abdominal pain and headache. In order to cut down the observed side effects, the drug has been modified into 5-aminosalicylic acid by linking to sulfapyridine through an azo bond with the projection that the modification would retain pharmacological abilities of SASP with minimal or none of the side effects. ${ }^{31}$ However, the effectiveness of the drug has been reported to be of varying degrees.

A number of products use various means of delivering mesalamine, or 5-aminosalicylic acid (5-ASA; Asacol, Pentasa, Rowasa), a topically active anti-inflammatory agent, to inflamed intestinal mucosa ${ }^{27,32,33}$ (Table 2). The newer 5-ASA agents are the drugs of choice for patients with IBD who are allergic to sulfa. Common side effects associated with 5-ASA agents include interstitial nephritis, pleuropericarditis, leukopenia and pancreatitis which are quite rare. On the other hand, side effects of sulfasalazine, which is used in low doses to maintain remission and in higher dosage in treating active UC, include nausea and headache. These side-effects can be minimized or avoided altogether by increasing the dosage slowly. Rashes, hemolytic anemia and hepatic toxicity are caused by sulfapyridine commonly. The medication should be discontinued immediately in cases these side effects. Sulfapyridine also causes decreased sperm function, a factor that has to be considered by patients desiring fertility.

Table 2 Common medical therapies for IBDs. ${ }^{27}$

\begin{tabular}{|c|c|c|c|}
\hline Medication & $\begin{array}{l}\text { Colon } \\
\text { activity }\end{array}$ & $\begin{array}{l}\text { Small-bowel } \\
\text { activity }\end{array}$ & $\begin{array}{l}\text { Side effect } \\
\text { degree }\end{array}$ \\
\hline \multicolumn{4}{|l|}{$\begin{array}{l}\text { 5-Acetylsalicylic } \\
\text { acid compounds }\end{array}$} \\
\hline Sulfasalazine & +++ & + & Intermediate \\
\hline Olsalazine & +++ & + & $\begin{array}{l}\text { Low to } \\
\text { intermediate }\end{array}$ \\
\hline Mesalamine & ++ & ++ & Low \\
\hline Mesalamine & +++ & + & Low \\
\hline Mesalamine enema & +++ & + & Very low \\
\hline Metronidazole & ++ & ++ & Intermediate \\
\hline Prednisone & +++ & +++ & Very high \\
\hline $\begin{array}{l}\text { Corticosteroid } \\
\text { enema }\end{array}$ & +++ & & $\begin{array}{l}\text { Low (but } \\
\text { avoid long- } \\
\text { term use) }\end{array}$ \\
\hline Mercaptopurine & +++ & +++ & High \\
\hline Methotrexate & +++ & +++ & High \\
\hline
\end{tabular}

Several chemical and physical modifications are marketed to minimize side effects and maximize delivery of the drug to the afflicted areas. One of them is Olsalazine which delivers intact 5-ASA to the terminal ileum by binding two 5-ASA molecules with a diazo bond, which is cleaved by bacteria. However the diazo group is responsible for ileal secretory diarrhea, a unique side effect of Olsalazine therapy which can be seen in 5 to 10 percent of patients. ${ }^{34}$ Rarely, the diarrhea can be quite severe. This drug has been shown to benefit UC patients. It can help maintain disease in remission. Not much information is available on the use of Olsalazine in CD patients, but it is logical 
to infer that the drug could be effective in these patients as well. In Mesalamine tablets, another form of the drug, 5-ASA is packaged in ethylcellulose microgranules which gradually release the drug in the jejunum to the colon. This drug has been found to be superior to placebo for the treatment of active $\mathrm{CD}$, as well as in maintaining its remission - something that has not been well demonstrated with sulfasalazine. ${ }^{35}$ A lower dosage (2-3g/day vs $4 \mathrm{~g}$ /day for $\mathrm{CD}$ ) is effective in patients with active UC. In a still lower dosage (1-2g/day), mesalamine is as effective as sulfasalazine in maintaining remission of UC. ${ }^{36}$ In another brand of mesalamine tablets, the drug is enveloped in a $\mathrm{pH}$-sensitive coating that delivers the drug to the distal ileum and colon. Most of the studies of this type of mesalamine tablet have been conducted in patients with UC. Dosages ranging from 2.4 to $4.6 \mathrm{~g}$ per day have been beneficial in the patients. ${ }^{37}$ This tablet has been found to be as effective as sulfasalazine in maintaining remission of UC. ${ }^{38,39}$ It has also been beneficial in the treatment of active CD and, in a dosage of $2.4 \mathrm{~g}$ per day, in maintaining remission. ${ }^{40}$ In enema or suppository form, mesalamine is the most effective therapy for distal proctosigmoiditis, but has little efficacy in anorectal CD. In proctitis, mesalamine enemas and suppositories are more effective than oral 5-ASA and slightly more effective than corticosteroid enemas or even oral prednisone. ${ }^{41}$ They work best when they are taken in the evening and retained all night. Although many patients improve after a few days of treatment, full benefit may not be achieved for 12 weeks. Mesalamine enemas, which may cost considerably more than oral medications have virtually no side effects because of little or no systemic 5-ASA absorption.

\section{Non-5-asa treatments}

\section{Antibiotics}

As clinical evidence suggests that excessive bacterial flora play significant role in the pathogenesis of IBDs, a number of antibiotics have been extensively tried. Virtually all studies performed in patients with $\mathrm{CD}$ have shown a benefit for antibiotic therapy in IBD. ${ }^{42}$ Metronidazole has been the best studied antibiotic in cases of IBD. This drug is fairly effective in patients with active $C D$ as it has potency similar to that of sulfasalazine. It has been found to be more effective in patients who have perianal $\mathrm{CD}$, and the benefits increase with dose (up to a maximum of $2 \mathrm{~g}$ per day). Some side effects like irreversible peripheral neuropathy can be associated with long term use of the drug. Another antibiotic Ciprofloxacin is also effective in patients with $\mathrm{CD}$, which can be used alone or in combination with metronidazole.

\section{Corticosteroids}

In cases of moderate to severe IBDs, corticosteroids have been the $1^{\text {st }}$ line of therapy for last three decades or more. ${ }^{43}$ They induce remission of active disease which can onwards be managed with 5-ASA compounds. These agents are not recommended for long term use due to the side effects which include osteopenia, weight gain, and glucose intolerance. Corticosteroids can be used systemically as well as locally. Initial treatment involves prednisone, 40 to $60 \mathrm{mg}$ per day. In severely ill hospitalized patients, reasonable initial therapy is hydrocortisone, $100 \mathrm{mg}$ administered intravenously every eight hours. Intravenous therapy generally produces rapid improvement of symptoms, with maximal benefit occurring when the corticosteroid has been administered for six to eight days.

Once improvements set in, prednisone is tapered off and finally discontinued. Concomitant use of 5-ASA agents can be helpful.
Alternatively, long-term alternate-day corticosteroid therapy can be used in patients with refractory CD ${ }^{44}$ Systemic corticosteroids use has extensive side effects profile which includes acne and severe mood changes, particularly common in young patients. Adrenal insufficiency can be triggered by biofeedback. Additionally infections can occur in patients who are receiving low doses or in patients who have just been tapered off of corticosteroids. Physical appearance can change because of steroid-induced hyperglycemia. Untimely cataract formation is another possible problem. The most dreaded side effect, which usually occurs in about 4.3 percent of patients receiving longterm high-dose corticosteroid therapy, is aseptic joint necrosis. ${ }^{45}$ To minimize the undesired effects of steroids, topical application by enema is practiced. Other alternatives are in development like fast degrading steroids such as Budesonide, tixocortol pivolate and fluticasone propionate which are still waiting for FDA approval. These newer corticosteroids are more rapidly metabolized than traditional corticosteroids, and they offer the promise of comparable efficacy with fewer systemic side effects. The packaging of these agents in a $\mathrm{pH}$-sensitive coating (similar to that used for 5-ASA preparations) offers the possibility of drug delivery to the small bowel and colon with aim to minimize side effects.

Two large prospective studies have shown that budesonide therapy is beneficial in patients with active CD. ${ }^{46}$ Studies are being conducted to determine the effectiveness of budesonide in treating UC and maintaining remission of $\mathrm{CD}$. Over time it will become more clear if budesonide and other newer corticosteroids truly provide therapeutic benefits with fewer side effects..$^{47,27}$

\section{Immunosuppressant drugs}

The suspicion of immune hyperactivity involvement in IBD has led to the use of immunosuppressant drugs which can be an invaluable adjunct in the treatment of patients with intractable inflammatory bowel disease or complex, inoperable perianal disease. ${ }^{48}$ Despite the fact that immunosuppressant agents have significant side effects, they are still safer and better tolerated in long term than corticosteroids. However, use of these agents in young patients who are candidates for surgery, or in patients who are noncompliant and refuse to return for periodic monitoring is not advisable. Various drugs of this class like azathioprine and mercaptopurine have been used to treat inflammatory bowel disease from early 1970s. Both Azathioprine and mercaptopurine are beneficial in 50 to 70 percent of patients suffering from intractable perianal CD. ${ }^{49}$ Not much information is available about their effectiveness in treating UC, although they have been beneficial in this disease. These drugs cause pancreatitis in 3 to 5 percent of patients, invariably during the first six weeks of therapy ${ }^{50}$ which limits their continued use. However, a retrospective review by Cornell et al. ${ }^{51}$ did not find a significant association between azathioprine and the development of lymphoma or leukemia. The drug, methotrexate, which has been used for intractable psoriasis and rheumatoid arthritis, has been shown to help 70 percent of patients with severe IBD, ${ }^{52}$ though it has a severe hepatotoxicity profile. Cyclosporine, commonly used in organ transplant, has also been used to treat IBD since 1980s in severely ill patients with UC who did not respond to corticosteroid therapy. ${ }^{53}$ In such patients, intravenously administered cyclosporine is highly effective for rapid disease control, and it may allow patients to avoid surgery. However, by end of first year, 70 to 80 percent of these patients may still require surgery. Thus, in many patients, the role of cyclosporine is to change a risky emergency procedure into a less urgent one..$^{54}$ 
Cyclosporine, a lipid bound agent, has been associated with an increased risk of seizures when it is administered to acutely ill, or severely malnourished patients who have low serum cholesterol/ lipid levels. Oral maintenance with cyclosporine has, at best, limited benefit with high relapse rate. The drug has a significant side effect profile that includes renal insufficiency and hypertension.

\section{Immunomodulators}

Anti-inflammatory treatments for treating IBD are driven by the idea that IBDs are caused by local inflammation. Accordingly antiinflammatory drugs like corticosteroids have been used extensively. With advent of molecular biology approaches, the search of molecular causes of IBD has been narrowed down to inflammation inducing pathways. Involvement of tumor necrosis factor alpha (TNF $\alpha$ ), a cytokine which plays a key role in immune hyper-responses, has been implicated in inducing inflammation in $\mathrm{IBD}^{55}$ and accordingly a number of pathway directed antibodies have been tried to treat IBD. Infliximab is a chimeric monoclonal antibody against TNF $\alpha$ is one of these. Another antibody interfering with TNF $\alpha$ pathway, adalimumab, is widely used for treating many diseases caused by autoimmune dysfunction like rheumatoid-, psoriatic-, and idiopathicarthritis, ankylosing spondylitis and IBDs. ${ }^{56}$ Another member of the same group of drugs is certolizumab pegol. It is also a monoclonal antibody which targets TNF $\alpha$. As TNF $\alpha$ is an essential component of immune response, use of these drugs can render an individual prone to various infections. In addition, these drugs are also known to have many other significant side effects. It is worth mentioning that almost half of the patients receiving these immunomodulators discontinue the treatment within 2-6 years either due to poor initial response or loss of response, or diverse adverse effects which outweigh the benefits. ${ }^{57,58}$ As previously mentioned, UC and IBD have a variety of causal factors and naturally responses of patients to an antibody treatment vary greatly. Antibodies targeting other molecules involved in the inflammatory pathways are being developed and tried in clinics.

\section{Surgical intervention}

Though surgery continues to be a central component in the treatment of patients IBD, ${ }^{59}$ intestinal resection of the affected part of the intestine is done only in extreme cases to remove partial blockage or perforation of the intestine. In addition to being more cost intensive, surgery alleviates the symptoms temporarily and often IBDs appear at the site of resection or at other sites. Therefore, experts advise that IBD should be treated with either limited resection or strictureplasty when possible to minimize the loss of bowel length. Surgical intervention is often accompanied with strictures leading to bowel obstruction. The stricture formation is initiated by scars formed after surgical resection; therefore, $\mathrm{CD}$ patients frequently require surgical procedure due to recurrence of the disease. ${ }^{60}$ Significant percentage of patients require reoperation within five years of the first one ${ }^{61}$ highlighting the fact that surgery offers only a temporary but a cost-intensive alternative.

\section{Stem cells}

Stem cells are a small percent of undifferentiated cells present in almost all organs of a body. With advancing age their numbers decrease; however, these cells can be isolated and reintroduced in an individual when needed. These cells behave slightly different in cell culture conditions which help in isolating them from other differentiated cells. Stem cells have immense ability to proliferate and to differentiate into other cell types of a body. In addition, stem cells have ability to find damaged tissue areas and they can proliferate and differentiate into the types of surrounding tissue cell types. ${ }^{62}$ Thus they offer a promising outlook for treating any degenerative disease including IBD. ${ }^{63}$ Stem cells can be isolated from one individual and grafted in same person or can be isolated from one individual and then grafted in different individual, which are known as autologous and allogenic grafts, respectively. Autologous grafts are usually a better option as they eliminate chances of inciting immunologic responses. However, in many individuals availability of autologous cells may not be possible because of feeble health condition. In those cases, allogenic grafts from HLA matched donors naturally becomes a more feasible and preferable choice especially knowing the fact that stem cells are quick in adapting to new in vivo surrounding. Though a limited experience is available with hematopoietic and mesenchymal stem cell transplantation for the treatment of these conditions, a number of clinical trials have yielded very encouraging results. Clerici et al. ${ }^{64}$ demonstrated that transplantation of hematopoietic stem cells could induce and maintain clinical and endoscopic remission in refractory $\mathrm{CD}$, which was associated with immunomodulation. ${ }^{64}$ Some tissues are comparatively richer in stem cell content so those tissues are more often used for preparation of stem cells and treatments which are discussed below.

\section{Hematopoietic stem-cell (HSC) therapy}

HSCs are multipotent cells with self-renewal property, are capable of differentiating into blood and immune cells. These stem cells can be isolated from the bone marrow (BM), umbilical cord blood, or more commonly from peripheral blood. ${ }^{65,66}$ They are progenitors of both myeloid (monocytes, erythrocytes macrophages, neutrophils, and dendritic cells) and lymphoid ( $\mathrm{T}$ cells, B cells, and natural killer cells) lineage cells. ${ }^{67}$ HSCs have been shown to be capable of directly migrating to a damaged tissue areas and then differentiate into epithelial or immunomodulatory cells in order to restore normal mucosal tissue. ${ }^{68}$

For autologous or allogenic HSC transplantation (HSCT), stem cells from the patient or from an HLA-matched donor (allogeneic) are pharmacologically mobilized after infusion of cyclophosphamide (CP) for 2 consecutive days to get rid of lymphocytes. Granulocyte colony-stimulating factor (G-CSF) is injected subcutaneously to stimulate BM to produce stem cells that are subsequently released into the bloodstream for 4-5 days prior to leukopheresis. ${ }^{69}$ Leukapheresis is performed to isolate CD34+ cells from the peripheral blood or $\mathrm{BM}$ and then cryopreserved until infusion. After immune ablation through chemotherapy to eliminate autoreactive cells, intravenous $\mathrm{CP}$ is administered with infusion of rabbit antithymocyte globulin (rbATG) 2 days after the first dose of CP. Methylpred-nisolone is also administered to improve tolerability. Transplantation of the isolated cells begins 5 days after the first administration of CP and 24 hours following the end of rbATG and methylprednisolone. The stem cells are then transplanted through a central venous catheter to the patient in varying dosages. Careful isolation is essential to reduce the risk of post-transplant morbidities and mortality. The process of engraftment and reconstitution of the immune system can last about 2-4 weeks. In the final phase of HSCT, where follow up is essential especially in allogenic HSCT, risk of chronic graft-versus-host disease (GvHD) can occur. In GvHD the activated donor effector cells attack the recipient's immune system. ${ }^{70}$ Mild forms of chronic GvHD can successfully be treated with steroids or immunosuppressive medications like Azathioprine. ${ }^{71}$ Patients are carefully and regularly followed up by 
their physicians at progressively increasing intervals i.e. at $1^{\text {st }}, 2^{\text {nd }}, 4^{\text {th }}$, $6^{\text {th }}, 12^{\text {th }}$, and $24^{\text {th }}$ months after discharging the patient.

Animal models provided first insight into utility of HSCT demonstrating that it could be an effective tool in treating autoimmune diseases. ${ }^{72}$ As stated above that autoimmune aggravation also can be contributing to IBD, immune suppression has been tried in treating IBD. In humans, HSCT was tried to treat malignant hematological indications in beginning ${ }^{73}$ and several case studies reported improvement in autoimmune disease patients following the HSCT for concomitant aplastic anemia or malignancy. ${ }^{74}$ In other cases where two patients with severe aplastic anemia underwent allogeneic BM transplant (BMT), their severe rheumatoid arthritis become quiescent in addition to resolution of the aplastic anemia and the reported remission lasted for 13 years. ${ }^{75}$ Findings, based on those studies and other phase I-II trials, showed that high-dose chemotherapy with autologous HSCT can successfully treat severe cases of various autoimmune diseases ${ }^{76}$ like multiple sclerosis, lupus, and rheumatoid arthritis, and others. The central part of HSCT effectiveness is to 'reset' the immune system by eliminating self-reactive T-lymphocytes and memory cells which serve as the effectors of a dysregulated immune system. ${ }^{77}$ Retrospective analyses and prospective studies show feasibility and safety of auto- and allo-HSCT in autoimmune diseases. $^{78,79}$ Results from the cohort of about 900 patients after autologous HSCT transplants for various indications, demonstrated a survival rate of $85 \%$ at 5 years out of which around $30 \%$ of patients showed a complete cure with full immune reconstitution..$^{79}$ Despite some discouraging outcomes in beginning, HSCT was tried in IBD, though first in patients with other indications (such as leukemia and non-Hodgkin's lymphoma (NHL)). First case of a CD patient, who underwent an autologous BMT for NHL in 1993, remissive state lasted for 6-months. ${ }^{80}$ Results of other studies varied but were promising, showing a remissive state for the primary indication along with clinical and endoscopic improvement for UC or CD ${ }^{80,81}$ Reconstitution of bone marrow with hematopoietic stem cells after complete immune ablation, the body is able to generate naïve lymphoid and myeloid cells ${ }^{82}$ thus reducing T-cell activity against mucosal selfantigens and limits local inflammatory process. Burt and colleagues included $24 \mathrm{CD}$ patients and demonstrated remission rates (defined as no need of supplementary medication) at $91 \%, 57 \%$, and $19 \%$ at years 1,3 , and 5 respectively. ${ }^{83}$ Another study showed all patients entered clinical remission at a 3-month follow up after transplantation; then at 16.5 -month follow up, $75 \%$ of patients remained in clinical and endoscopic remission. ${ }^{84}$ However, the studies mentioned above involved a limited sample size. There is a need for long-term follow up and randomized control studies with larger cohorts of patients.

Oyama and colleagues also showed improvement with hematopoietic autologous peripheral blood (PB) HSCT with lowdose CP and G-CSF. ${ }^{85}$ At the 18.5 month follow up, 11 out of 12 patients were off all immunosuppressive drugs and had achieved clinically significant remission. It is important to note this study measured clinical outcomes and did not report any endoscopic findings. Another phase I and II trial carried out by Hasselblatt and colleagues assessed the outcomes of 12 patients with refractory CD undergoing autologous PB HSCT with immunoablation conditioning. ${ }^{86}$ Mobilization was carried out with $\mathrm{CP}$ and G-CSF followed by harvesting CD30 positive PBSCs. More than half (around $56 \%$ ) of the patients showed clinical and endoscopic improvements in response to the mobilization procedure. Continuing with nine patients entering the conditioning phase, five patients remained in a remissive state at the 6-month follow up. One of these patients showed complete remission of pyoderma gangrenosum extraintestinal manifestation, and another patient had a complete fistula closure. However, seven of the nine patients had a relapse of disease at the 3-year follow-up. It is encouraging to note that mucosal healing achieved in this study $(56 \%$ of patients) was noticeably higher than in previous results of phase II trials involving TNF- $\alpha$ pathway inhibitors as a mode of therapy but with no transplant. ${ }^{87}$

A multicenter randomized phase III interventional study, carried out by the European Group for Blood and Marrow Transplantation (EBMT) aimed to test the potential clinical benefits of high-dose immunoablation of early versus delayed (59 weeks) auto-HSCT. ${ }^{88}$ All 45 patients of both were mobilized prior to randomization. The early group received immediate HSCT 4 week post-leukapheresis, while the control delay group waited a year for transplantation, but continued conventional therapy. A stringent primary endpoint for full clinical remission was defined by a CD Activity Index (CDAI) score (150 or less), no use of corticosteroid, immunosuppressive, or biologic drugs for the last 3 months, and finally, no evidence of active disease along any part of the GI tract by endoscopic or radiological imaging. Secondary set of endpoints were the individual components of the primary composite outcome along with labs, QoL, and imaging. Results from this study revealed that only 2 out of 23 patients from the early treatment group achieved full clinical and endoscopic remission compared to only 1 out of 22 from the controlled delay group. This study demonstrated no statistical difference in sustained disease remission between the HSCT-treated groups versus conventional therapy controls. The trial also stated that all patients experienced non-serious adverse complications, like infections as the most common. One patient in the early treatment group died 20 days after the conditioning phase, due to sinusoidal obstructive syndrome. The authors concluded the study against widespread use of HSCT for patients with refractory CD; a stark contrast from the preliminary results, showing promising durable benefit 1 year after transplant. The authors did address the stringent endpoint to justify treatment toxicity. However, before dismissing the widespread use of HSCT for refractory CD patients it is important to dissect the suboptimal end points used in the study design. ${ }^{89}$ If a patient did not meet any composite criteria, the transplant was classified as a failed treatment, including use of corticosteroid or immunosuppressive drugs. Maintenance of a immunosuppressive regimen could have had a positive impact on the rates of remission. Studies have shown induction should include maintenance therapy in order to prevent relapse of disease. ${ }^{83}$ A different conclusion can be reached, if the endpoints were less demanding and maintenance therapy was maintained after transplant for this difficult-to-treat refractory patient population. Allogeneic HSCT has the ability to genetically correct the underlying disease with a healthy donor.$^{81}$ However, it is associated with a higher risk of complication and mortality rate when compared to auto-HSCT. There is also a high risk of a noninfectious adoptive autoimmunity transfer of IBD, leading to a phenotypic manifestation in patients receiving allogeneic BMT.

Although the limited number of phase I-III trials show promising results, the occurrence of relapse makes it difficult to categorize HSCT as a complete curative treatment when remission rates drop from $91 \%$ at 1 year to $19 \%$ at 5 years and therefore long-term outcome assessments are necessary. ${ }^{83}$ It is also interesting that most studies did not initiate any form of combination therapy post-transplant. Future studies could look into the safety and efficacy of combination therapy 
following the HSCT. Expert transplant centers should collaborate to continue biobanking and grow the registry of both successful and unsuccessful HSCT cases. Having more information about individual cases will provide new insights into treatment mechanisms leading to improvements in transplant protocols. A risk-benefit analysis must be fully discussed with the patient before initiating treatment.

\section{Mesenchymal stem cells (MSCs)}

MSCs have garnered a strong interest from both academic and industry based researchers who share the goal of expanding the therapeutic use of cells for treating diverse degenerative, inflammatory and immune-mediated diseases. Friedenstein and colleagues first described the mesenchymal stem- cell concept in 1974 when it was isolated from BM..$^{90}$ MSCs are multipotent cells that are present in all tissues and are capable of differentiating into several types of cells. ${ }^{66}$ The cells can be successfully isolated from umbilical cord blood or adipose tissue for clinical application..$^{91,92}$ Adipose-derived stem cells can easily be prepared in large quantities with reduced morbidity and discomfort for the patient. There has been a flood of scientific publications using MSCs, their use in clinical trials, and possible commercialization. Findings in animal models fueled the interests in MSCs' use in treating IBDs. Interest in use of MSCs to treat IBD further has ignited and skyrocketed because of their abilities to find damaged tissue areas, to suppress inflammation, and, to promote tissue healing. ${ }^{93,94}$ Also, MSCs can be easily isolated in a good number from various organs such as bone marrow, umbilical cords, fetal liver, muscle, lungs and adult adipose tissues. ${ }^{95-97}$ Because of presence of comparatively high number of stem cells in adipose tissues and relative ease of isolation, these have been major source of stem cells recently. The reports include new developments in four major areas which may be of key importance to future successful use of MSC-based therapies in a numbers of patients: (a) Understanding of fundamental biology of the primary cells in bone marrow and other tissues that give rise to MSCs in culture. (b) Mechanisms by which MSCs modulate immune and inflammatory responses in vivo. (c) Insights into MSC kinetics, safety, and efficacy in relevant animal disease models. (d) Isolation, definition, and clinical trial-based testing of human MSCs by biomedical companies and academic medical centers. Despite this progress, it remains unclear whether MSCs will enter mainstream therapeutic practice as a frequently used alternative to pharmacotherapy or surgical/radiological procedures in the foreseeable future. Many clinical trials using MSCs in human have been carried out and they have been found to be safe without any acute toxicity and without any ectopic grafting. Promising results have been recorded in CD associated fistula as well. A study by Melief et al..$^{98}$ demonstrated that BM and adipose-derived MSCs have similar immune-modulating functions and multilineage differentiation potential, while adipose tissue had more potent modulating property over the BM-derived cells secondary to increased levels of cytokine secretion. The International Society for Cellular Therapy has set defining characteristics for a stem cell to be labeled as mesenchymal when they: (1) have the ability to adhere to plastic under standard culture conditions; (2) express CD105, CD73, and CD90 but do not express CD45, CD34, CD14, CD11b, CD79 $\alpha$, CD19, or HLA-class II molecules; and (3) have multipotent in vitro differentiation potential to osteoblasts, adipocytes and chondroblasts. ${ }^{99}$

In addition to differentiation, and more relevant to clinical practice, MSCs have immunomodulating capabilities to downregulate mucosal immune reactivity and promote tissue healing. ${ }^{100}$ Additional studies show that MSCs have the ability to inhibit T-cell proliferation in vitro, ${ }^{101,102}$ and inhibit lymphocyte proliferation by activating a programmed cell death pathway. ${ }^{103}$ The specific immunomodulating mechanisms of MSCs are still unclear, but evidence shows that they influence target cells within close proximity and are not solely dependent on cell-to-cell contact. ${ }^{104}$ Promising results demonstrate the functional ability of MSCs to influence the immune response and dampen inflammation, affirming their clinical importance for therapeutic transplantation in autoimmune diseases.

Administration of MSCs is way more advantageous over HSCT due to their low immunogenic property which eliminates a need for chemotherapy, a necessary and costly step in HSCT. The low immunogenicity of MSCs can be attributed to the fact that they express low levels of major histocompatability complex (MHC) class I, no MHC class II, and no co-stimulatory molecules which activate T cells. ${ }^{104}$ Low immunogenicity gives allogeneic MSCs the ability to evade the immune system and allow their usage across MHC barriers. ${ }^{105}$ Due to the non immunogenic properties and ease of isolation and expansion, unmatched allogeneic MSCs are advantageous because they can be mass expanded making it easier for midsize transplant centers to provide their patients with the possibility of transplantation. On a cautionary note, Nauta and colleagues demonstrated that MCSs are not always intrinsically immuno-privileged. Under certain conditions, allogeneic MSCs can cause stimulation of memory T-cell response leading to graft rejection. ${ }^{106}$

MSCs have been used to treat CD in systemic (intra-arterial or intravenous) transplantation for active luminal disease or local administration for fistulizing disease. There are only a handful of studies that report on mesenchymal stem cell transplantation (MSCT) for $\mathrm{CD}$ and UC. ${ }^{107,108}$ At least $25 \%$ of CD patients develop debilitating perianal fistulas within 20 years of first diagnosis, ${ }^{109}$ while complex fistulas present $78 \%$ of the times, and are discernibly more difficult to treat over simple ones. Treatments for such fistulas have shifted from a surgery-based approach to a more immunosuppressant- and biologic-based step-wise approach. Unfortunately despite the best medical advances, durable fistula closure rates remain at dismal 37 percent. ${ }^{110}$

In regards to local administration, currently accepted forms of treatment by using MSCs in IBD are indicated for the fistulizing phenotype in CD. Two studies in 2013 studied fistula response to either autologous MSCs or allogeneic adipose MSCs. Autologous treatment showed complete fistula healing in $82 \%$ (27 out of 33) of patients after 8 weeks of final injection..$^{70}$ The allogeneic treatment demonstrated full closure in only $30 \%$ of the patients, though remaining patients showed a reduction of drainage from fistula tracts. ${ }^{111}$ Local administration of autologous MSCs was shown to be well tolerated and feasible in another study that included $10 \mathrm{CD}$ patients with actively-draining complex perianal and enterocutaneous fistulas. ${ }^{112}$ Following ex vivo isolation and expansion, all patients showed either complete or partial fistula closure without any adverse effects. All patients showed a reduction in disease activity, most often after the second administration.

However, drawbacks of auto-MSCT are seen with the efficacy of harvesting time, which requires several weeks for ex vivo expansion. In comparison, allogeneic transplants seem to be more convenient in terms of time and feasibility because of MSCs low immunogenicity. In a study by Molendijk and colleagues, which is the first placebo controlled, double-blinded, randomized, dose-escalating clinical trial to date, ${ }^{113} 21 \mathrm{CD}$ patients suffering from perianal fistulas underwent local administration of allogeneic BM MSCs various number of cells. 
Administration of 30million cells was most effective with an $85.7 \%$ successful fistula healing rate at week 12 (more than that in patients receiving either 10 or 90 million cells); only $33 \%$ showed healing for the placebo group. Throughout the 24-week trial period, no serious adverse events occurred.

Systemic infusions of MSCs for treating luminal CD also have been tried. Unique to MSCs, an 'off-the-shelf' product (Prochymal) has been developed by a third-party laboratory Osiris Therapeutics Inc. (USA). These cells are isolated from the BM of healthy donors and expanded ex vivo. The MSCs purified by Osiris are cultured and packaged. Remarkably, up to 10,000 dosages can be obtained from a single donor. Several phase I-II studies included the Prochymal MSC product for transplant. The first human trial of systemic MSCs was carried out by Onken and colleagues ${ }^{114}$ and they evaluated in nine patients with active $\mathrm{CD}$, who previously had failed immunosuppressants and a course of steroids. Patients were randomized to receive Prochymal allogeneic MSCs in varying doses intravenously. A total of 3 out of 10 patients achieved clinical remission by day 14 following the transplantation. No serious adverse events occurred during treatment in any of the groups while infusions were well tolerated. Duijvestein and colleagues ${ }^{115}$ showed that autologous BM MSCT appeared to be well tolerated and feasible in the treatment of refractory luminal CD and no serious adverse events occurred during harvesting and IV administration.

In a phase II study, carried out by Forbes and colleagues studied clinical response at 42 days after a 4-week course of allogeneic infusions of MSCs. ${ }^{116}$ Among the 15 patients, a reduction in the CDAI score was seen along with 8 patients entering clinical remission. Results from a randomized double-blind, multicenter phase 3 study of allogeneic expanded adipose-derived stem cells ${ }^{117}$ on 212 patients with complex active perianal fistulas demonstrated a positive impact of MSC transplantation. Patients received a single injection of either 120 million MSCs or placebo. The primary end point (measured at week 24) was combined remission (absence of fistula discharge and $<2 \mathrm{~cm}$ of fluid collection, based on magnetic resonance imaging analysis). A significantly greater percentage of patients receiving MSCs achieved remission $(49.5 \%)$ than patients given placebo (34.3\%). Median time to clinical remission was 6.7 weeks for MSC treatment vs 14.6 weeks for placebo. Cell therapy was well tolerated, with a lower proportion of patients experiencing treatment-related adverse events compared with placebo: $17.5 \%$ vs $29.4 \% .{ }^{117}$

Notwithstanding the promising improvement of clinical outcomes, it is necessary to consider the current hazard and safety before enrolling a patient for MSCT. A few studies isolated various modes of MSCs to verify the risk for chromosomal aberration development after long-term culturing or induction of tumors during in vitro and in vivo experiments. ${ }^{118}$ Culture standards need to be perfected, and all possible hazards in the cell sample need to be eliminated before administration. Several phase I-III trials were carried out with historical or concomitant immunomodulating therapy. A study by Duijvestein and colleagues investigated the effect of immunosuppressive drugs (i.e., azathioprine, methotrexate, 6-MP, and anti-TNF $\alpha$ ) on the MSC phenotype, survival, and differentiation or immunosuppressive capacity. Their results confirmed mesenchymal stromal cell function was not affected by common drugs used for treating refractory IBD patients. ${ }^{119}$ Moreover, anti-TNF $\alpha$ antibodies, used for inhibiting inflammatory pathway, enhanced the inhibitory effect, suggesting clinical safety and usefulness of combination therapy.
As discussed in existing literature, there is a complex and variety of pathways and mechanisms through which MSCs respond to damaged inflamed tissue in the gut which is not well understood. Future studies should focus on the exact mechanism by which MSCs operate may provide vital information to improve on current therapeutic strategies. It is also valuable to explore combination therapy following transplantation to improve remission-rates and -duration. ${ }^{119}$ Continuing exploration of other stem-cell sources in animal models and preclinical set up is essential. In addition to an understanding of basic science, the protocols for isolation and administration should improve as we move forward towards stem-cell therapies for refractory CD patients and other autoimmune diseases.

\section{Induced pluripotent stem cells (iPSCs)}

A fact that mature differentiated cells can be reprogrammed to become pluripotent was established more than half a century ago. ${ }^{120}$ These cells are called as iPSCs and hold great potential in the area of regenerative medicine. Cells in embryonic-like cell stage, achieved by the introduction of specific transcription factors (Oct4, Sox2, Klf4, and c-Myc), ${ }^{121}$ have vast capacity to differentiate in multiple types and have infinite ability to propagate. These properties make them ideal for replacing damaged cells in diseased tissue. In addition use of iPSCs eliminates the ethical issue that exists with the use of ESCs. An innovative protocol has been published for the direct generation of intestinal tissue from human embryonic stem cells (ESCs) and iPSCs in vitro, by manipulating growth factors. ${ }^{122}$

Since one of the contributing causes of IBD is suspected to be rooted in immunological etiology, approaches to alter immune system by stem cells also have been tried. Regulatory T cells (Tregs) can be used to affect autoimmunity and avoid organ rejection. Difficulty lies in the fact that Tregs are difficult to isolate in sufficient amount. Haque et al. ${ }^{123}$ provided an approach to generate functional Tregs, induced by iPSCs. ${ }^{123}$ Adoptive cell transfer (ACT) of Tregs showed encouraging results in experimental settings for autoimmune diseases such as rheumatoid arthritis ${ }^{124}$ and systemic lupus, ${ }^{125}$ but had significant risk of teratoma formation as seen in case of ESCs. ${ }^{126}$

Animal and human models using iPSCs in IBD have not yet been explored, and there is limited literature on case studies for iPSCs used to treat autoimmune diseases. Further development of novel therapeutic strategies should involve extensive research and safety assessment to eliminate risk factors associated with the transplant before it is introduced in the clinical environment.

\section{Mechanism of action of stem cells}

Stem cells are multipotent cells which can generate at least osteogenic, chondrogenic and adipogenic cells. In addition, these cells are immunomodulatory as they secrete a number of cytokines, chemokines and growth factors. Because of their multi-potential ability, they can and do perform a number of functions in their new surroundings also. The qualities which make MSCs useful for treating these degenerative conditions also make it equally difficult to establish the mechanism by which they help the recipients. Three qualities of the stem cells are important to consider when thinking about the way they can help heal. Stem cells have unparalleled ability to find damaged tissues in body and they can comfortably home there. They actively proliferate and daughter cells differentiate into cells of that organ and thus minimize the damage incurred by the disease to the organ of in focus. They also secrete a number of anti-inflammatory cytokines to dampen local inflammation. ${ }^{127,128}$ Simultaneously, they 
can neutralize the inflammatory cytokines secreted by the host tissue also. MSCs also modulate the immune response by suppressing T-cell proliferation and thus dampen the immunogenic response in IBD
(CD or UC) patients. ${ }^{129} \mathrm{~A}$ possible mechanism of action of MSCs in degenerative intestinal diseases is displayed in Figure 2.

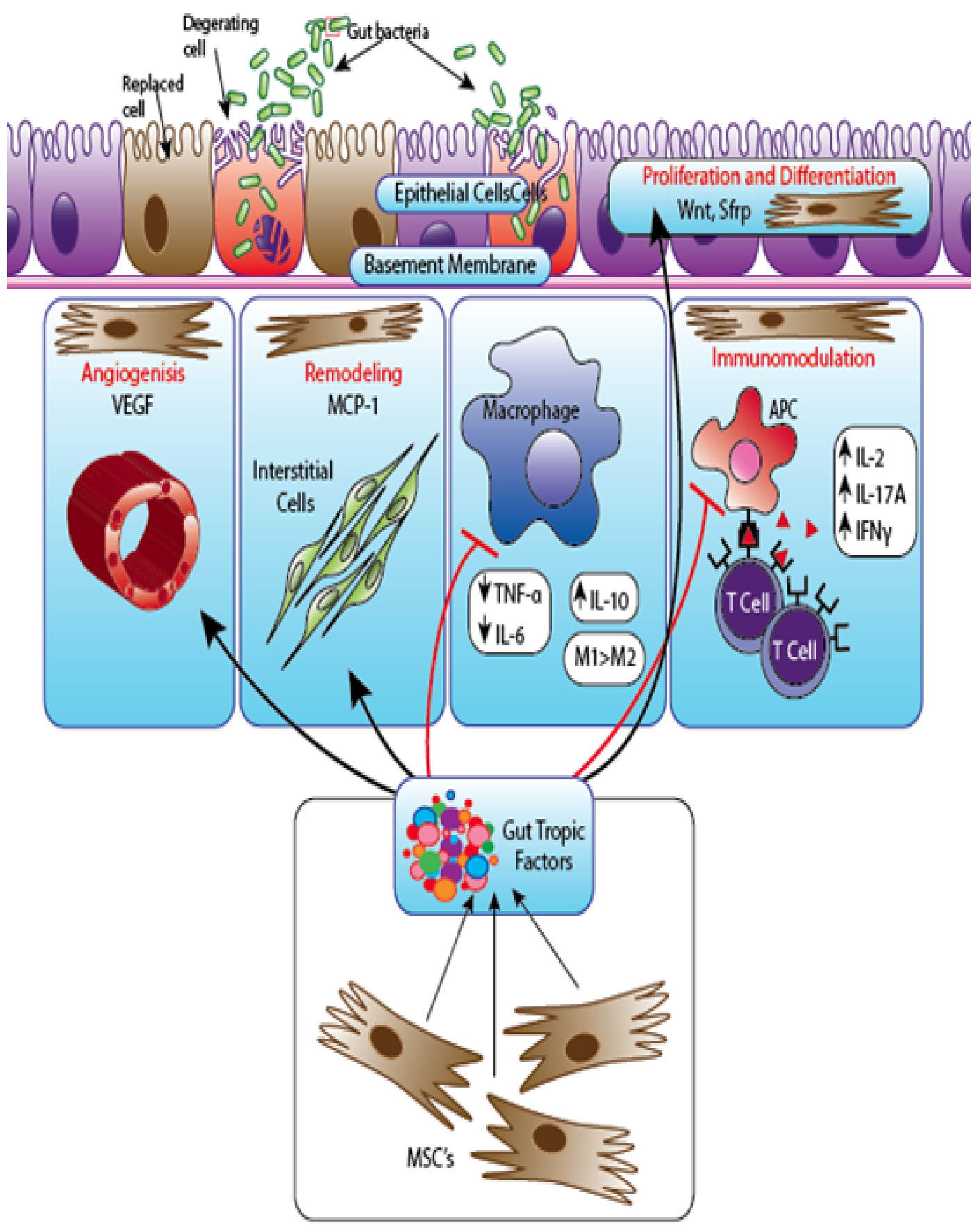

Figure 2 Proposed mechanisms of action of mesenchymal stem cells (MSCs) in inflammatory bowel disease: In Crohn's disease loss of the epithelium and decreased antimicrobial defense lead to an increased exposure to agents which activate the innate immune cells of the lamina propria. Activated mature antigen presenting cells (APCs) acquire the ability to drive T cell differentiation and activation into effector cells (IFNc producing ThI or IL I 7-producing Th I 7, depending on the nature of the response). An inflammatory infiltrate with a ThI and ThI7 phenotype accumulates in the lamina propria. Increased proinflammatory cytokine production by APCs and macrophages induces upregulation of adhesion molecules in both lymphatic and blood vessels that irrigate the intestinal mucosa and produce chemotactic factors, favoring recruitment of leucocytes and therefore further amplifying the inflammatory response. Transplanted MSCs migrate to inflamed tissues where they promote epithelial regeneration and tissue healing, and exert immuno-regulatory functions (left part of the figure). MSCs inhibit APC maturation, T cell proliferation and IFNc production. Transplanted adipose-derived MSCs also decrease production of pro-inflammatory cytokines such as IL6,TNF $\alpha$ and ILI 2 by lamina propria mononuclear cells. Furthermore MSCs can produce both ILI 0 and TGF $\beta$, which inhibit ThI differentiation while promoting Treg differentiation, and restoring tolerance. IFN, interferon; IL, interleukin;TGF $\beta$, transforming growth factor $\beta$; TNF $\alpha$, tumor necrosis factor $\alpha$. 


\section{Conclusion}

The objective of treating IBDs stays the same i.e. to get long term remission of the disease and delay, if not avoid, intestinal degeneration altogether. Established therapies for IBD have been dominated by the focus on inflammation and on immunological abnormalities in its pathogenesis. Drugs targeting the three major etiologies of IBD (i.e. inflammation, bacterial over load, and autoimmune activity) have been in clinical practice for a long time. Unfortunately these drugs are not always effective and have significant undesired side effects. The optimal IBD therapy should aim for complete cure, block inflammation, enhance proliferation, and coordinate remodeling during the healing process. Furthermore, when examining the overall depiction of health in the intestine. Intestinal homeostasis should be regulated by extraintestinal as well as local machinery. Consequently, therapeutic targets should transform inflammatory cells to intestinal (stem) cells, stromal cells, or bone marrow (stem) cells, and biologics should evolve into stem cell-based or gene-based therapy. Regenerative medicine translated from stem cell biology must provide a backbone to such a paradigm shift in the next-generation of therapeutics for IBD.

Hematopoietic and mesenchymal stem cells have been shown to be a potential alternative therapy for disease control in refractory $\mathrm{CD}$. Continued in-depth investigation is warranted to fully understand the complex cellular mechanisms. The information from current ongoing phase III clinical trials will provide a valuable roadmap for the future of stem-cell therapy. Cellular therapies must not be limited to utilizations of HSCs or MSCs. Other cellular therapies should continue to be explored in preclinical settings. Stem cell therapy provides a new therapeutic alternative to address this debilitating health issue without many of the side effects seen with conventional medications. Transplantation of cells from other individuals can be immunogenic and thus can cause an immunogenic response in the recipient. However, stem cells are often not immunogenic as they differentiate and thus mend into the recipient's tissue type. Though there is a dearth of literature on any adverse effects of stem cell immunogenicity or rejection, few reports indicate that there are some undesired ill effects or no effect at all. Despite some setbacks, clinical trials have been undertaken which demonstrate that MSC are helpful in treating IBD. At present about 40 clinical trials using stem cells for treating IBD have been registered at the clinical trials website (https://clinicaltrials.gov). A number of trials indicate that stem cells hold great promise for cell-based therapy in general. ${ }^{116}$ Still there are many challenges, such as which type of stem cells is most suitable to achieve optimal immunosuppression and tissue healing. Further studies are also needed to standardize and determine optimal dosing and where in the conventional treatment algorithms this therapy should be placed. Systemic infusion of stem cells in clinic still faces multiple development challenges although findings from preclinical models have revealed the impressive immunomodulatory effects of MSCs. They have sparked a considerable interest among scientists and clinicians, and offer great hope to desperate patients. However, the translation of stem cell science into clinical practice still remains in a relatively primitive state. Still, early results suggest several inherent problems in using stem cells in treating IBDs in human. In each study, optimization of MSC therapy emerges to be the most urgent problem, and can be resolved only by scientifically unveiling the mechanisms of therapeutic action. Future investigations must focus on perfecting safety and feasibility, with the goal of improving quality of life for the patient.

\section{Acknowledgements}

None.

\section{Conflict of interest}

The author declares no conflict of interest.

\section{References}

1. Mitchell A, Guyatt G, Singer J, et al. Quality of life in patients with inflammatory bowel disease. J Clin Gastroenterol. 1988;10(3):306-310.

2. Zand A, van Deen WK, Inserra EK, et al. Presenteeism in inflammatory bowel diseases: A hidden problem with significant economic impact. Inflamm Bowel Dis. 2015;21(7):1623-1630.

3. http://www.cdc.gov/ibd/ibd-epidemiology.htm

4. Damle RN, Cherng NB, Flahive JM, et al. Clinical and financial impact of hospital readmissions after colorectal resection: Predictors, outcomes, and costs. Dis Colon Rectum. 2014;57(12):1421-1429.

5. Park KT, Bass D. Inflammatory bowel disease-attributable costs and cost-effective strategies in the united states: a review. Inflamm Bowel Dis. 2011;17(7):1603-1609.

6. Heslop JA, Hammond TG, Santeramo I, et al. Concise review: workshop review: understanding and assessing the risks of stem cell-based therapies. Stem cells translational medicine. 2015;4(4):389-400.

7. Broberger O, Perlmann P. Autoantibodies in human ulcerative colitis. $J$ Exp Med. 1959;110(5):657-674.

8. Wen Z, Fiocchi C. Inflammatory bowel disease: Autoimmune or immune-mediated pathogenesis? Clin Dev Immunol. 2004;11(3-4):195-204.

9. Korsmeyer SJ, Williams RC, Wilson ID, et al. Lymphocytotoxic antibody in inflammatory bowel disease: A family study. The New England journal of medicine. 1975;293:1117-1120.

10. Das KM, Biancone L. Is IBD an autoimmune disorder? Inflammatory Bowel Diseases. 2008;14(Suppl 2):S97-S101.

11. Duerr RH, Targan SR, Landers CJ, et al. Neutrophil cytoplasmic antibodies: A link between primary sclerosing cholangitis and ulcerative colitis. Gastroenterology. 1991;100(5 pt 1):1385-1391.

12. Taniguchi M, Geng X, Glazier KD, et al. Cellular immune response against tropomyosin isoform 5 in ulcerative colitis. Clinical immunology. 2002;101(3):289-295.

13. Ebert EC, Geng X, Bajpai M, et al. Antibody to tropomyosin isoform 5 and complement induce the lysis of colonocytes in ulcerative colitis. $\mathrm{Am}$ J Gastroenterol. 2009;104:2996-3003.

14. Halme L, Paavola Sakki P, Turunen U, et al. Family and twin studies in inflammatory bowel disease. World J Gastroenterol. 2006;12(23):36683672 .

15. Ogura $\mathrm{Y}$, Bonen $\mathrm{DK}$, Inohara $\mathrm{N}$, et al. A frameshift mutation in nod2 associated with susceptibility to crohn's disease. Nature. 2001;411(6837):603-606.

16. Prescott NJ, Fisher SA, Franke A, et al. A nonsynonymous snp in ATG1611 predisposes to ileal crohn's disease and is independent of CARD15 and IBD5. Gastroenterology. 2007;132(5):1665-1671.

17. Sewell GW, Marks DJ, Segal AW. AW The immunopathogenesis of crohn's disease: A three-stage model. Curr Opin Immunol. 2009;21(5):506-513.

18. Diegelmann J, Czamara D, Le Bras E, et al. Intestinal DMBT1 expression is modulated by crohn's disease-associated IL23R variants and by a DMBT1 variant which influences binding of the transcription factors CREB1 and ATF-2. PloS one. 2013;8(11):e77773. 
19. Chermesh I, Azriel A, Alter-Koltunoff M, et al. Crohn's disease and SLC11A1 promoter polymorphism. Digestive Diseases and Sciences. 2007;52(7):1632-1635

20. Dessein R, Chama illard M, Danese S Innate immunity in Crohn's disease: the reverse side of the medal. J Clin Gastroenterol. 2008;42(Suppl 3 Pt 1):S144-S147.

21. Martinez Montiel MP, Munoz Yague MT. Biologic therapies for chronic inflammatory bowel disease. Revista Espanola de Enfermedades Digestivas: Organo Oficial de la Sociedad Espanola de Patologia Digestiva. 2006;98(4):265-291.

22. Hendrickson BA, Gokhale R, Cho JH. Clinical aspects and pathophysiology of inflammatory bowel disease. Clin Microbiol Rev. 2002;15(1):79-94.

23. Bielefeldt K, Davis B, Binion DG. Pain and inflammatory bowel disease. Inflamm Bowel Dis. 2009;15(5):778-788

24. http://www.niddk.nih.gov/health-information/health-topics/digestivediseases/crohns-disease/Pages/facts.aspx.

25. Danese S, Fiocchi C. Ulcerative Colitis. The New England journal of medicine. 2011;365:1713-1725.

26. Varzari A, Deyneko IV, Tudor E, et al. Polymorphisms of glutathione $\mathrm{S}$-transferase and methylenetetrahydrofolate reductase genes in Moldavian patients with ulcerative colitis: Genotype-phenotype correlation. Meta Gene. 2016;7:76-82.

27. Botoman VA, Bonner GF, Botoman DA. Management of inflammatory bowel disease. American Family Physician. 1998;57(1):57-68.

28. Thomas A, Lodhia N. Advanced therapy for inflammatory bowel disease: A guide for the primary care physician. Journal of the american board of family medicine. 2014;27(3):411-420.

29. Peyrin Biroulet L, Lemann M. Review article: Remission rates achievable by current therapies for inflammatory bowel disease. Aliment Pharmacol Ther. 2011;33(8):870-879.

30. Allgayer H. Sulfasalazine and 5-ASA compounds. Gastroenterology clinics of North America. 1992;21(3):643-658.

31. Galvez J, Garrido M, Merlos M, et al. Intestinal anti-inflammatory activity of ur-12746, a novel 5-asa conjugate, on acute and chronic experimental colitis in the rat. Br J Pharmacol. 2000;130(8):1949-1959.

32. Brzezinski A, Rankin GB, Seidner DL, et al. Use of old and new ora 5-aminosalicylic acid formulations in inflammatory bowel disease. Cleveland Clinic Journal of Medicine. 1995;62(5):317-323.

33. Bonner GB RW. 5-aminosalicylic acid preparations in the treatment of inflammatory bowel disease. Inflammopharmacology. 1993;2(3):247262.

34. Stenson W. Inflammatory bowel disease. In: T Y, editor. Textbook of gastroenterology. USA: Lippincott; 1995. p. 1748-1805.

35. Gendre JP, Mary JY, Florent C, et al. Oral mesalamine (Pentasa) as maintenance treatment in Crohn's disease: a multicenter placebo-controlled study. The Groupe d'Etudes Thérapeutiques des Affections Inflammatoires Digestives (GETAID). Gastroenterology. 1993;104(2):435-439.

36. Mulder CJ, Tytgat GN, Weterman IT, et al. Double-Blind Comparison of Slow-Release 5-Aminosalicylate and Sulfasalazine in Remission Maintenance in Ulcerative Colitis. Gastroenterology. 1988;95(6):14491453.

37. Schroeder KW, Tremaine WJ, Ilstrup DM. Coated oral 5-aminosalicylic acid therapy for mildly to moderately active ulcerative colitis. A randomized study. N Engl J Med. 1987;317(26):1625-1629.
38. Riley SA, Mani V, Goodman MJ, et al. Comparison of delayed-release 5-aminosalicylic acid (mesalazine) and sulfasalazine as maintenance treatment for patients with ulcerative colitis. Gastroenterology. 1988;94(6):1383-1389.

39. Riley SA, Mani V, Goodman MJ, et al. Comparison of delayed release 5 aminosalicylic acid (mesalazine) and sulphasalazine in the treatment of mild to moderate ulcerative colitis relapse. Gut. 1988;29(5):669-674.

40. Prantera C, Pallone F, Brunetti G, et al. Oral 5-aminosalicylic acid (asacol) in the maintenance treatment of crohn's disease. The italian ibd study group. Gastroenterology. 1992;103(2):363-368.

41. Group D-A. Topical 5-aminosalicylic acid versus prednisolone in ulcerative proctosigmoiditis. A randomized, double-blind multicenter trial Danish 5-asa group. Dig Dis Sci. 1987;32(6):598-602.

42. Spirt MJ. Antibiotics in inflammatory bowel disease: New choices for an old disease. The American Journal of Gastroenterology. 1994;89(7):974-978.

43. Hanauer SB, Baert F. Medical therapy of inflammatory bowel disease. The Medical clinics of North America. 1994;78(6):1413-1426.

44. Bello C, Goldstein F, Thornton JJ. Alternate-day prednisone treatment and treatment maintenance in crohn's disease. Am J Gastroenterol. 1991;86(4):460-466.

45. Vakil N, Sparberg M. Steroid-related osteonecrosis in inflammatory bowel disease. Gastroenterology. 1989;96(1):62-67.

46. Sachar DB. Budesonide for inflammatory bowel disease. It is a magic bullet? N Engl J Med. 1994;331(13):873-874.

47. Hirschfeld S, Clearfield HR. Pharmacologic therapy for inflammatory bowel disease. American Family Physician. 1995;51(8):1971-1975.

48. Sandborn WJ. A review of immune modifier therapy for inflammatory bowel disease: Azathioprine, 6-mercaptopurine, cyclosporine, and methotrexate. Am J Gastroenterol. 1996;91(3):423-433.

49. Pearson DC, May GR, Fick GH, et al. Azathioprine and 6-mercaptopurine in crohn disease. Ann Intern Med. 1995;123(2):132-142.

50. Haber CJ, Meltzer SJ, Present DH, et al. Nature and course of pancreatitis caused by 6-mercaptopurine in the treatment of inflammatory bowel disease. Gastroenterology. 1986;91(4):982-986.

51. Connell WR, Kamm MA, Dickson M, et al. Long-term neoplasia risk after azathioprine treatment in inflammatory bowel disease. Lancet. 1994:343(8908):1249-1252.

52. Botoman VA. Inflammatory bowel disease. In: RB T, editor. Difficult medical management. USA: Saunders; 1991. p. 374-386.

53. Lichtiger S, Present DH, Kornbluth A, et al. Cyclosporine in severe ulcerative colitis refractory to steroid therapy. $N$ Engl J Med. 1994;330(26):1841-1845.

54. Kozarek R, Bedard C, Patterson D, et al. Cyclosporin use in the precolectomy chronic ulcerative colitis patient: A community experience and its relationship to prospective and controlled clinical trials. Pacific northwest gastroenterology society. Am $J$ Gastroenterol. 1995;90(12):2093-2096.

55. Danese S, Fiorino G, Reinisch W. Review article: Causative factors and the clinical management of patients with crohn's disease who lose response to anti-tnf-alpha therapy. Aliment Pharmacol Ther. 2011;34(1):1-10.

56. Danese S. Adalimumab for ulcerative colitis: a little is better than none? Inflamm Bowel Dis. 2012;18(4):793-794.

57. Sands BE. New drugs on the horizon for IBD. Dig Dis. 2014;32(Suppl 1):74-81. 
58. Berns M, Hommes DW. Anti-TNF-alpha therapies for the treatment of crohn's disease: The past, present and future. Expert opinion on investigational drugs. 2016;25(2):129-143.

59. Cima RR, Pemberton JH. Surgical management of inflammatory bowel disease. Current treatment options in gastroenterology. 2001;4(3):215225 .

60. Fazio VW, Tjandra JJ, Lavery IC, et al. Long-term follow-up of strictureplasty in crohn's disease. Diseases of the colon and rectum. 1993;36(4):355-361.

61. Tjandra JJ, Fazio VW. Strictureplasty for ileocolic anastomotic strictures in crohn's disease. Dis Colon Rectum. 1993;36(12):1099-1103.

62. Srivastava AS, Shenouda S, Mishra R, et al. Transplanted embryonic stem cells successfully survive, proliferate, and migrate to damaged regions of the mouse brain. Stem cells. 2006;24(7):1689-1694.

63. Irhimeh MR, Cooney J. Management of inflammatory bowel disease using stem cell therapy. Curr Stem Cell Res Ther. 2015;11(1):72-77.

64. Clerici M, Cassinotti A, Onida F, et al. Immunomodulatory effects of unselected haematopoietic stem cells auto transplantation in refractory crohn's disease. Dig Liver Dis. 2011;43(12):946-952.

65. Kashyap A, Forman SJ. Autologous bone marrow transplantation for non-hodgkin's lymphoma resulting in long-term remission of coincidental crohn's disease. British journal of haematology. 1998;103(3):651-652.

66. Da Silva Meirelles L, Chagastelles PC, Nardi NB. Mesenchymal stem cells reside in virtually all post-natal organs and tissues. Journal of cell science. 2006;119(pt 11):2204-2213.

67. Pittenger MF, Mackay AM, Beck SC, et al. Multilineage potential of adult human mesenchymal stem cells. Science. 1999;284(5411):143147.

68. Kavanagh DP, Kalia N. Hematopoietic stem cell homing to injured tissues. Stem cell reviews. 2011;7(3):672-682.

69. Sallerfors B, Olofsson T. Granulocyte-macrophage colony-stimulating factor (gm-csf) and granulocyte colony-stimulating factor (g-csf) secretion by adherent monocytes measured by quantitative immunoassays. European journal of haematology. 1992;49(4):199-207.

70. Lee WY, Park KJ, Cho YB, et al. Autologous adipose tissue-derived stem cells treatment demonstrated favorable and sustainable therapeutic effect for crohn's fistula. Stem cells. 2013;31(11):2575-2581.

71. Iwasaki T. Recent advances in the treatment of graft-versus-host disease. Clin Med Res. 2004;2(4):243-252.

72. Ikehara S. Treatment of autoimmune diseases by hematopoietic stem cell transplantation. Experimental hematology. 2001;29:661-669.

73. Bierman PJ, Sweetenham JW, Loberiza FR, et al. Syngeneic hematopoietic stem-cell transplantation for non-hodgkin's lymphoma: A comparison with allogeneic and autologous transplantation-the lymphoma working committee of the international bone marrow transplant registry and the european group for blood and marrow transplantation. J Clin Oncol. 2003;21(20):3744-3753.

74. Van Deen W. Hematopoietic stem cells: New research: Nova Science. 2012 .

75. Lowenthal RM, Cohen ML, Atkinson K, et al. Apparent cure of rheumatoid arthritis by bone marrow transplantation. J Rheumatol. 1993;20(1):137-140.

76. Gratwohl A, Passweg J, Bocelli Tyndall C, et al. Autologous hematopoietic stem cell transplantation for autoimmune diseases. Bone marrow transplant. 2005;35(9):869-879.
77. Martinez Montiel MP, Gomez Gomez GJ, Flores AI. Therapy with stem cells in inflammatory bowel disease. World $J$ Gastroenterol. 2014;20(5):1211-1227.

78. Daikeler T, Hugle T, Farge D, et al. Allogeneic hematopoietic sct for patients with autoimmune diseases. Bone marrow transplant. 2009;44(1):27-33.

79. Farge D, Labopin M, Tyndall A, et al. Autologous hematopoietic stem cell transplantation for autoimmune diseases: An observational study on 12 years' experience from the european group for blood and marrow transplantation working party on autoimmune diseases. Haematologica. 2010;95(2):284-292.

80. Drakos PE, Nagler A. Case of crohn's disease in bone marrow transplantation. Am J Hematol. 1993;43(2):157-158.

81. Lopez Cubero SO, Sullivan KM, McDonald GB. Course of crohn's disease after allogeneic marrow transplantation. Gastroenterology. 1998;114(3):433-440.

82. Swenson E, Theise N. Stem cell therapeutics: Potential in the treatment of inflammatory bowel disease. Clin Exp Gastroenterol. 2010;3:1-10.

83. Burt RK, Craig RM, Milanetti F, et al. Autologous nonmyeloablative hematopoietic stem cell transplantation in patients with severe anti-tnf refractory crohn disease: Long-term follow-up. Blood. 2010;116(26):6123-6132.

84. Cassinotti A, Annaloro C, Ardizzone S, et al. Autologous haematopoietic stem cell transplantation without cd34+ cell selection in refractory crohn's disease. Gut. 2008;57(2):211-217.

85. Oyama Y, Craig RM, Traynor AE, et al. Autologous hematopoietic stem cell transplantation in patients with refractory crohn's disease. Gastroenterology. 2005;128(3):552-563.

86. Hasselblatt P, Drognitz K, Potthoff K, et al. Remission of refractory crohn's disease by high-dose cyclophosphamide and autologous peripheral blood stem cell transplantation. Aliment Pharmacol Ther. 2012;36(8):725-735.

87. Hanauer SB. Infliximab: Lifetime use for maintenance is appropriate in crohn's disease. A balancing view: Lifetime channeling of infliximab for crohn's disease. Am J Gastroenterol. 2005;100(7):1438-1439.

88. Hawkey CJ, Allez M, Clark MM, et al. Autologous hematopoetic stem cell transplantation for refractory crohn disease: A randomized clinical trial. Jama. 2015;314(23):2524-2534.

89. Hommes DW, Lacey PN. Stem cells: HSCT for Crohn's disease: Work in progress or a bridge too far? Nat Rev Gastroenterol Hepatol. 2016;13(3):128-130.

90. Friedenstein AJ, Chailakhyan RK, Latsinik NV, et al. Stromal cells responsible for transferring the microenvironment of the hemopoietic tissues. Cloning in vitro and retransplantation in vivo. Transplantation. 1974;17(4):331-340.

91. Sensebe L, Krampera M, Schrezenmeier H, et al. Mesenchymal stem cells for clinical application. Vox sang. 2010;98(2):93-107.

92. Mulder GD, Lee DK, Jeppesen NS. Comprehensive review of the clinical application of autologous mesenchymal stem cells in the treatment of chronic wounds and diabetic bone healing. Int Wound J. 2012;9(6):595-600.

93. Chamberlain G, Fox J, Ashton B, et al. Concise review: Mesenchymal stem cells: Their phenotype, differentiation capacity, immunological features, and potential for homing. Stem cells. 2007;25(11):2739-2749.

94. Chamberlain G, Smith H, Rainger GE, et al. Mesenchymal stem cells exhibit firm adhesion, crawling, spreading and transmigration across aortic endothelial cells: Effects of chemokines and shear. PloS one. 2011;6(9):e25663. 
95. Bianco P, Robey PG, Simmons PJ. Mesenchymal stem cells: Revisiting history, concepts, and assays. Cell stem cell. 2008;2(4):313-319.

96. Boquest AC, Shahdadfar A, Brinchmann JE, et al. Isolation of stromal stem cells from human adipose tissue. Methods Mol Biol. 2006;325:3546.

97. Zhu M, Heydarkhan Hagvall S, Hedrick M, et al. Manual isolation of adipose-derived stem cells from human lipoaspirates. $J$ Vis Exp. 2013;79:e50585.

98. Melief SM, Geutskens SB, Fibbe WE, et al. Multipotent stromal cells skew monocytes towards an anti-inflammatory interleukin-10-producing phenotype by production of interleukin-6. Haematologica. 2013;98(6):888-895.

99. Dominici M, Le Blanc K, Mueller I, et al. Minimal criteria for defining multipotent mesenchymal stromal cells. The international society for cellular therapy position statement. Cytotherapy. 2006;8(4):315-317.

100. Stappenbeck TS, Miyoshi H. The role of stromal stem cells in tissue regeneration and wound repair. Science. 2009;324(5935):1666-1669.

101. Bartholomew A, Sturgeon C, Siatskas M, et al. Mesenchymal stem cells suppress lymphocyte proliferation in vitro and prolong skin graft survival in vivo. Exp Hematol. 2002;30(1):42-48.

102. Le Blanc K, Tammik C, Rosendahl K, et al. HLA expression and immunologic properties of differentiated and undifferentiated mesenchymal stem cells. Experimental hematology. 2003;31(10):890-896.

103. Augello A, Tasso R, Negrini SM, et al. Bone marrow mesenchymal progenitor cells inhibit lymphocyte proliferation by activation of the programmed death 1 pathway. Eur J Immunol. 2005;35(5):1482-1490.

104. Ankrum JA, Ong JF, Karp JM. Mesenchymal stem cells: Immune evasive, not immune privileged. Nature biotechnology. 2014;32:252-260.

105. Schu S, Nosov M, O’Flynn L, et al. Immunogenicity of allogeneic mesenchymal stem cells. Journal of cellular and molecular medicine. 2012;16(9):2094-2103.

106. Nauta AJ, Westerhuis G, Kruisselbrink AB, et al. Donor-derived mesenchymal stem cells are immunogenic in an allogeneic host and stimulate donor graft rejection in a nonmyeloablative setting. Blood. 2006;108(6):2114-2120.

107. Lazebnik LB, Lychkova AE, Knyazev OV. Treatment of experimental ulcerative colitis. Bulletin of experimental biology and medicine. 2012;153(6):889-892.

108. Liang J, Zhang H, Wang D, et al. Allogeneic mesenchymal stem cell transplantation in seven patients with refractory inflammatory bowel disease. Gut. 2012;61(3):468-469.

109. Hellers G, Bergstrand O, Ewerth S, et al. Occurrence and outcome after primary treatment of anal fistulae in crohn's disease. Gut. 1980;21(6):525-527.

110. Molendijk I, Nuij VJ, Van der Meulen-de Jong AE, et al. Disappointing durable remission rates in complex crohn's disease fistula. Inflamm Bowel Dis. 2014;20(11):2022-2028.

111. De la Portilla F, Alba F, Garcia Olmo D, et al. Expanded allogeneic adipose-derived stem cells (eascs) for the treatment of complex perianal fistula in crohn's disease: results from a multicenter phase I/IIa clinical trial. Int J Colorectal Dis. 2013;28(3):313-323.

112. Ciccocioppo R, Bernardo ME, Sgarella A, et al. Autologous bone marrow-derived mesenchymal stromal cells in the treatment of fistulising crohn's disease. Gut. 2011;60(6):788-798
113. Molendijk I, Bonsing BA, Roelofs $\mathrm{H}$, et al. Allogeneic bone marrow-derived mesenchymal stromal cells promote healing of refractory perianal fistulas in patients with crohn's disease. Gastroenterology. 2015;149(4):918-927.

114. Onken JGD, Hanson J, Pandak M, et al. Successful outpatient treatment of refractory crohn's disease using adult mesenchymal stem cells. American College of Gastroenterology Conference. 2006.

115. Duijvestein M, Vos AC, Roelofs H, et al. Autologous bone marrow-derived mesenchymal stromal cell treatment for refractory luminal crohn's disease: Results of a phase i study. Gut. 2010;59(12):1662-1669.

116. Forbes GM, Sturm MJ, Leong RW, et al. A phase 2 study of allogeneic mesenchymal stromal cells for luminal crohn's disease refractory to biologic therapy. Clin Gastroenterol Hepatol. 2014;12(1):64-71.

117. Panés J, García-Olmo D, Van Assche G, et al. A phase iii randomised controlled trial of cx601, expanded allogeneic adipose-derived mesenchymal stem cells (easc), for complex perianal fistulas in crohn's disease. Lancet. 2016;10(Suppl 1):388.

118. Tarte K, Gaillard J, Lataillade JJ, et al. Clinical-grade production of human mesenchymal stromal cells: Occurrence of aneuploidy without transformation. Blood. 2010;115(8):1549-1553.

119. Duijvestein M, Molendijk I, Roelofs H, et al. Mesenchymal stromal cell function is not affected by drugs used in the treatment of inflammatory bowel disease. Cytotherapy. 2011;13(9):1066-1073.

120. Gurdon JB. The developmental capacity of nuclei taken from intestinal epithelium cells of feeding tadpoles. J Embryol Exp Morphol. 1962;10:622-640.

121. Takahashi K, Yamanaka S. Induction of pluripotent stem cells from mouse embryonic and adult fibroblast cultures by defined factors. Cell. 2006;126(4):663-676.

122. Spence JR, Mayhew CN, Rankin SA, et al. Directed differentiation of human pluripotent stem cells into intestinal tissue in vitro. Nature. 2011;470(7332):105-109.

123. Haque R, Lei F, Xiong X, et al. Programming of regulatory t cells from pluripotent stem cells and prevention of autoimmunity. J Immunol. 2012;189(3):1228-1236.

124. Wright GP, Notley CA, Xue SA, et al. Adoptive therapy with redirected primary regulatory $t$ cells results in antigen-specific suppression of arthritis. Proc Natl Acad Sci USA. 2009;106(45):19078-19083.

125. Scalapino KJ, Daikh DI. Suppression of glomerulonephritis in nzb/nzw lupus prone mice by adoptive transfer of ex vivo expanded regulatory cells. PloS One. 2009;4(6):e6031.

126. Knoepfler PS. Deconstructing stem cell tumorigenicity: A roadmap to safe regenerative medicine. Stem cells. 2009;27(5):1050-1056.

127. De Girolamo L, Lucarelli E, Alessandri G, et al. Mesenchymal stem/ stromal cells: A new "cells as drugs" paradigm. Efficacy and critical aspects in cell therapy. Curr Pharm Des. 2013;19(13):2459-2473.

128. Panes J, Salas A. Mechanisms underlying the beneficial effects of stem cell therapies for inflammatory bowel diseases. Gut. 2009;58(7):898900 .

129. Scaldaferri F, Vetrano S. Mesenchymal stem cells in IBD: Unmascing their therapeutic mechanisms. Dig Dis Sci. 2015;60(7):1873-1875. 